\title{
Correction to: The listed, delisted, and sustainability of therapeutic medicines for dementia patients: the study is specific to South Korea
}

\author{
Jong Hoon Lee ${ }^{1} \mathbb{C}$
}

Published online: 7 March 2022

(c) The Author(s) 2022

\section{Correction to: Naunyn-Schmiedeberg's Archives of Pharmacology https://doi.org/10.1007/s00210-022-02209-3}

In the published version of this article, Fig. 3 caption contained mistake.

The Fig. 3 caption should read as below:

Fig. 3 The expanded users of donepezil (D), rivastigmine $(\mathrm{R})$, memantine $(\mathrm{M})$, and death tolls. The donepezil trend line is black. Deaths per 100,000 people increase in the cubic polynomial equation $(R 2=0.929)$. The rivastigmine trend line is red. The death toll graph for rivastigmine increases rapidly from the year 2012 to the year 2018 in the cubic polynomial equation $(R 2=0.855)$. The memantine trend line is green. Memantine death tolls increase or decrease in the 6th-degree polynomial equation $(R 2=0.941)$

This is being corrected in this publication.

Publisher's note Springer Nature remains neutral with regard to jurisdictional claims in published maps and institutional affiliations.

The original article can be found online at https://doi.org/10.1007/ s00210-022-02209-3.

Jong Hoon Lee

science@ research.re.kr

1 Science \& Research Center, Seoul National University

College of Medicine, Seoul, South Korea 